\title{
Elderly Fall and Glaucoma: Vision Assessment in Geriatrics
}

\author{
(1) Sunny Chi Lik Au1, (D) Simon Tak Chuen Ko² \\ 1 Pamela Youde Nethersole Eastern Hospital, Clinic of Special Out Patient, Hong Kong, China \\ 2Tung Wah Eastern Hospital, Clinic of Ophthalmology, Hong Kong, China
}

\section{To the editor,}

A 67-year-old glaucoma man fell on level ground with left sided tripod fracture (Figure 1). He suffered from both eyes primary open angle glaucoma, but failed pharmacological treatment and trabeculectomy surgery. His visual field (VF) loss is extensive, (Figure 2), so left eye Baerveldt glaucoma implant, followed by right eye Ahmed glaucoma valve were implanted for intraocular pressure control.

Primary glaucoma, being a top cause of blindness worldwide, is generally more prevalent in elderly (1). Secondary glaucoma like angle closure, phacomorphic glaucoma are particularly related to aging cataract lens. Fall in geriatric glaucoma patients is not rare, and occasionally causes serious sequelae (2).

Vision assessment not only counts on visual acuity (VA), but also contrast sensitivity, colour vision and VF. In geriatric patients, both near and distance VA should be assessed, as uncorrected presbyopia is common cause for poor vision, where management is simply a pair of glasses. VA charts' testing with black letters on white background is under high contrast, thus possibly missing early diagnosis of glaucoma patients who suffered slight decrease in contrast sensitivity only (3). Loss in contrast sensitivity is associated with increased falls in elderly, and sometimes explain discrepancy between reasonable acuity in clinic, but poor functional vision in dimly lit elderly home (4). Vistech chart, Pelli-Robson chart or Cambridge chart are possible testing tools for contrast sensitivity, and aiding diagnosis of low vision and glaucoma. Most optic neuropathies give characteristic red-green colour deficiency, however in early glaucoma, blue-yellow colour deficiency is detected instead (5).

VF testing helps detecting and monitoring diseases of optic nerve and intracranial visual pathway. Normal VF is 50, 60, 70 and 90-degree respectively over superior, nasal, inferior and temporal directions. However, refractive status, VA, presence of dermatochalasis, senile ptosis and tremor in old people could hinder a reliable interpretation of VF defect. In clinic, simplest qualitative method for peripheral VF is by confrontation, whereas central 10-degree by Amsler grid. For more accurate and detailed quantification, perimetry could be used. Kinetic perimetry is based on a moving stimulus of known luminance from a non-seeing area to a seeing area. In contrast, static perimetry involves a static on-off stimuli of variable luminance presented throughout the potential field. Automated static perimetry is commonly used for glaucoma progression analysis, (Figure 2) yet patient's cooperation and concentration is of paramount importance, which sometimes is difficult for the elderly.

Mobility helps people to navigate, driving and continue to use public transport with confidence. Elderly mobility is particularly affected by inferior and central field defects, and geriatricians should bear in mind for assessing rehabilitation potential. In glaucoma patients, common visual field defects include blind spot enlargement, nasal stepping, or paracentral scotoma in early stage; progressing to arcuate scotoma later, subsequently enlarging to become altitudinal field defects in late stage. Eventually, only residual temporal or central island of vision left form dense constriction of peripheral fields (Figure 2), before complete blindness occurs.

In conclusion, contrast sensitivity and VF are important parameters for vision assessment in elderly, coincidentally glaucoma causes loss in both.

Keywords: Vision, glaucoma, computed tomography, eye

Peer-review: Externally peer-reviewed.

Address for Correspondence: Sunny Chi Lik Au, Pamela Youde Nethersole Eastern Hospital, Clinic of Special Out Patient, Hong Kong, China Phone: +852 21626909 E-mail: kilihcua@gmail.com ORCID: orcid.org/0000-0002-5849-3317

Received: 25 Dec, 2019 Accepted: 20 Jan, 2020

Cite this article as: Au SCL, Ko STC. Elderly Fall and Glaucoma: Vision Assessment in Geriatrics. Eur J Geriatr Gerontol 2020;2(2):60-61 


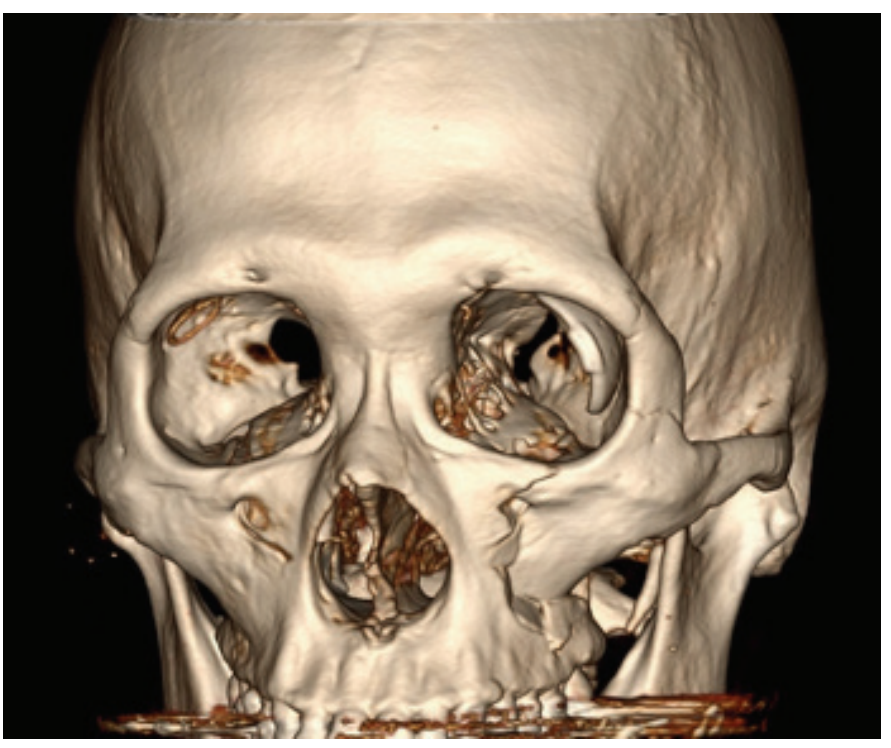

Figure 1. Computed tomography of the skull and face. Left tripod fracture is evidenced by cracks over zygomatic arch, lateral and inferior orbital wall. The large plate of Baerveldt glaucoma implant and the small ring-shaped Ahmed glaucoma valve implant could be seen respectively over left and right orbit

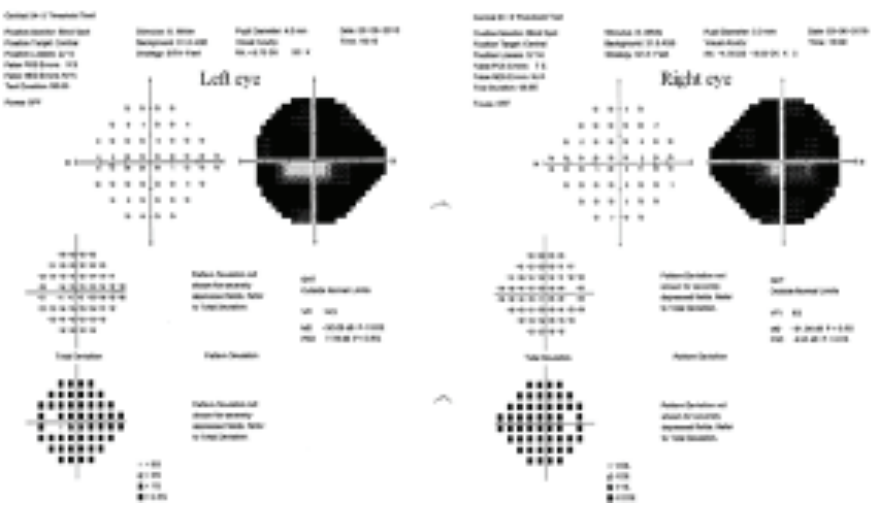

Figure 2. Visual Field test by static automated Humphrey 24-2 perimetry. This Threshold test showed bilateral altitudinal defects over superior field, and bilateral dense constriction over peripheral inferior fields, more severe over right eye. Residual central island of vision left was 10 -degree and $<5$ degree for left and right eye respectively

\section{Authorship Contributions}

Concept: S.C.L.A.U., Design: S.C.L.A.U., Data Collection or Processing: S.C.L.A.U., Analysis or Interpretation: S.C.L.A.U., Literature Search: S.C.L.A.U., Writing: S.C.L.A.U., S.T.C.K.

Conflict of Interest: Authors have declared no conflicts of interest.

Financial Disclosure: The authors declared that this study received no financial support.

\section{References}

1. Bourne RRA, Jonas JB, Bron AM, Cicinelli MV, Das A, Flaxman SR, Friedman DS, KEeffe JE, Kempen JH, Leasher J, Limburg H, Naidoo K, Pesudovs $K$, Peto T, Saadine J, Silvester AJ, Tahhan N, Taylor HR, Varma R, Wong TY, Resnikoff S, Vision Loss Expert Group of the Global Burden of Disease Study. Prevalence and causes of vision loss in high-income countries and in Eastern and Central Europe in 2015: magnitude, temporal trends and projections. Br J Ophthalmol 2018;102:575-585.

2. Ramulu PY, van Landingham SW, Massof RW, Chan ES, Ferrucci L, Friedman DS. Fear of falling and visual field loss from glaucoma. Ophthalmology 2012;119:1352-1358.

3. Bambo MP, Ferrandez B, Güerri N, Fuertes I, Cameo B, Polo V, Larrosa JM, Garcia-Martin E. Evaluation of Contrast Sensitivity, Chromatic Vision, and Reading Ability in Patients with Primary Open Angle Glaucoma. J Ophthalmol 2016;2016:7074016.

4. Saftari LN, Kwon OS. Ageing vision and falls: a review. J Physiol Anthropol 2018;37:11.

5. Papaconstantinou D, Georgalas I, Kalantzis G, Karmiris E, Koutsandrea C, Diagourtas A, Ladas I, Georgopoulos G. Acquired color vision and visual field defects in patients with ocular hypertension and early glaucoma. Clin Ophthalmol 2009;3:251-257. 